\title{
Fernando Rodríguez Mansilla, El Inca Garcilaso en su Siglo de Oro, Madrid / Frankfurt am Main, Iberoamericana / Vervuert, 2019 (Biblioteca Indiana, 48), 235 pp. ISBN: 978-84-9192-052-6
}

\section{Daniela Oyola Valdez}

Pontificia Universidad Católica del Perú

PERÚ

daniela.oyolav@pucp.edu.pe

[Hipogrifo, (issn: 2328-1308), 8.2, 2020, pp. 893-897]

Recibido: 19-08-2020 / Aceptado: 14-09-2020

DOI: http://dx.doi.org/10.13035/H.2020.08.02.56

Enrique Cortez acierta cuando afirma que la crítica garcilasista nace por oposición, al emerger en el siglo XX «como el producto de un conflicto de interpretaciones»?, no solo porque es en la primera década del 1900 cuando recién empieza el estudio sistemático sobre el Inca Garcilaso de la Vega, sino porque esta conflictividad se vuelve una especie de marca discursiva del diálogo intertextual sobre el autor. La razón de su carácter polémico es el desafío que supone tratar la ambigua relación entre la figura y la obra, derivada del tono autobiográfico que recorre los textos del cuzqueño. A esto se le sumó la asunción del Inca como emblema desde el que se desplegaba el debate sobre la «cuestión del mestizaje» en el Perú, al punto de asignarle el título de «primer peruano». Pero la pregunta es si se puede hablar de autobiografía, de mestizaje y de peruanidad en los siglos XVI y XVII, tal como se entiende hoy en día. Continuando y reforzando la polemicidad característica de la crítica garcilasista, Fernando Rodríguez Mansilla trae de vuelta un acercamiento filológico en El Inca Garcilaso en su Siglo de Oro que, tomando distancia de postulados recientes, propone «de nuevo» conocer al Inca a partir de sus escritos.

El título es sugestivo al sintetizar el contenido del estudio en dos sentidos. Por un lado, porque el contexto y los principios discursivos del periodo áureo suponen la base sobre la que se sostiene la propuesta total. Por otro lado, porque es esta

1. Cortez, Enrique, «La ficción garcilasista: el Inca Garcilaso de la Vega en la narrativa peruana», Revista de Crítica Literaria Latinoamericana, 70, 2009, p. 138. 
alusión a la posesión lo que permitirá abogar por concepciones del Garcilaso histórico, del enunciador de su obra y de la relación particular entre ambos. Precisamente, uno de los elementos más valiosos del libro es su severo y permanente cuestionamiento al paradigma que ha dominado los estudios coloniales de las últimas décadas, a partir del cual se ha consolidado una crítica garcilasista que comete el grave error, a ojos del autor, de tener los ojos más en el presente que en el pasado. Rodríguez Mansilla prefiere, por el contrario, evitar la supuesta oscilación entre timidez, subversión, simulación, disidencia antimonárquica y otros rasgos atribuidos a la figura del Inca, que han terminado por convertirlo en mito.

El primer capítulo consiste en la presentación de las premisas y los conceptos que dirigen el análisis de todo el libro, a la par que devela varias inconsistencias de la crítica reciente, procedentes de lecturas que obedecerían más a expectativas contemporáneas, que predisponen el hallazgo de contradicciones y silencios textuales. Para la «detonación del mito»², el Siglo de Oro constituye el eje argumentativo, lo que supone el detenimiento en las particularidades estético-literarias del discurso historiográfico áureo y humanista, así como la dependencia a la evidencia documental tanto sobre la biografía como sobre los horizontes de producción y recepción textual de la época. El autor se distancia de la valoración de Garcilaso por su condición racial y propone estudiarlo como un intelectual a secas, situado en la España del XVI y XVII. Así, en vez de la creencia de que la vida del Inca engendra su obra, asume que es el texto quien inventa al hombre. Esto implica tomar por objeto de estudio a la «persona» del historiador, al que entiende como fenómeno eminentemente textual, derivado de la autoconfiguración del productor de un proyecto historiográfico planificado desde la traducción de los Diálogos de León Hebreo. Por ende, la concepción ciceroniana de la historia como magistra vitae (o modelo de vida) y del historiador como sabio y guía, son los preceptos que dirigen una empresa textual que pretende sumar al capital cultural del proyecto político-imperial español.

El segundo capítulo inicia el análisis de la obra total, el cual se desarrolla de forma cronológica para el examen de la «evolución» de las marcas textuales de Garcilaso, que se consolidan gradualmente hasta el texto póstumo. Rodríguez Mansilla propone que ya en la traducción de los Diálogos se pueden encontrar las características de la «persona» de la textualidad del Inca. En tanto la traducción es concebida como una práctica formativa en la tradición áurea, el cuzqueño la realiza en aras de iniciar su posicionamiento como historiador dentro del prestigioso círculo intelectual cordobés que frecuentaba de forma cercana. Esta búsqueda no solo es indicio de su cómoda y poco problemática inserción social en el contexto hispánico, sino que además da lugar a que la concepción de la patria lejana y la expresión del orgullo cuzqueño sean perfectamente compatibles dentro de una propuesta de escritura imperial. Lejos de contradicciones autobiográficas inherentes, producto

2. La frase es de Zac Zimmer, en referencia al procedimiento del narrador de la novela Poderes secretos (1995) de Miguel Gutiérrez, en la que precisamente se realiza un cuestionamiento explícito de lo construido por la crítica garcilasista en torno al Inca Garcilaso. Ver Zimmer, Zac, «El escándalo del mestizaje: Miguel Gutiérrez reescribe al Inca Garcilaso», Revista de Crítica Literaria Latinoamericana, 43, 85, 2017, pp. 497-517. 
de una lectura «a capricho», modernizante y romántica, el crítico aboga por un control autorial desplegado de inicio a fin y procedente del neoplatonismo del que se nutre el Inca por medio de los Diálogos y del entorno intelectual. En ese sentido, la biografía es ante todo un elemento retórico para la construcción de su «persona».

El tercer capítulo, dedicado a la Relación de la descendencia de Garci Pérez de Vargas, contiene una de las premisas más persuasivas: la distinción entre la obra inédita y la obra publicada de Garcilaso es vital para un análisis verdaderamente completo. La dimensión autobiográfica de la Relación permite validar conclusiones sobre el resto de la obra, pero por contraste, esto es, al haber sido desestimada por su propio autor del proyecto oficial debido a los excesos y las vacilaciones personalistas que el escritor del XVI entiende incompatibles con el ideal del edificio historiográfico. En tanto el texto buscaba establecer un vínculo con un familiar poderoso, traza un legado caballeresco y modélico que viene desde Garci Pérez, el cual abraza y dignifica la herencia del padre del Inca y así opaca la traición que famosamente se le acusó. Si las digresiones íntimas son bienvenidas en la Relación, esto es porque se orientan a un fin ajeno a la empresa historiográfica. La diferencia entre esta y los otros títulos permite entonces el reconocimiento de la sofisticación de las operaciones discursivas de los últimos, orientadas a un proyecto intelectual y de mayor dimensión.

En el siguiente capítulo se subraya la influencia de la escuela historiográfica promovida por Ambrosio de Morales, reconocido cronista y padre figurativo de Garcilaso ${ }^{3}$, en La Florida del Inca. La crónica sobre la fracasada empresa de Hernando de Soto sería, pues, expresión de la ligazón indestructible entre materia y forma, derivada de una rigurosa construcción escritural dirigida a la justificación del imperio español a través de la extensión del mito goticista hasta la conquista americana. En la representación resalta la equiparación entre romanos, españoles e indios en materia de virtud y religiosidad, la cual se extiende hasta convertir al imperio incaico en un capital cultural que consolide el poderío español. Esto supone otra gran prueba de su consciencia intelectual, al entender que el seguimiento de la escuela de Morales asegura su persona de historiador; por ende, la prueba de una labor letrada en ningún sentido marginal.

El cuarto y el quinto capítulo están dedicados a las dos partes de la obra más importante de Garcilaso, cúspide de su empresa historiográfica. En el cuarto apartado, Rodríguez Mansilla se vale de un enfoque reciente dentro del estudio del Siglo de Oro español, al situar la primera mitad de los Comentarios reales dentro del debate peninsular sobre el pauperismo urbano del XVII y las propuestas reformistas de carácter secular y moderno. Este le permite demostrar la consolidación de los elementos textuales que el Inca ha venido definiendo. Así, el enunciador como sabio neoestoico a partir de la «autoridad del fracaso», la maestría compositiva en su inclusión de digresiones y la narración de una traslatio imperii son perfectamen-

3. En una carta a Eusebio Asensio, Garcilaso le expresa el agradecimiento hacia el cronista por haber favorecido su traducción del Hebreo: «fue tanta la merced que me hizo, que me adoptó por hijo y tomó por suyos mis trabajos, y se lo llevó Dios quando más lo uve menester». Ver Asencio, Eusebio, «Dos cartas desconocidas del Inca Garcilaso», Nueva Revista de Filología Hispánica, 7, 3/4, 1953, pp. 583-593. 
te visibles en su tratamiento de la pobreza en el mundo incaico y en los primeros años de la conquista. Destaca la concepción de Viracocha como «padre» que fija un origen común entre españoles e indios, quienes pertenecerían a una misma genealogía a nivel mitológico. Se prueba de nuevo un discurso contextualizado en la Península, en tanto las concepciones andinas son resignificadas mediante nociones europeas y, en ese sentido, hacen dialogar al discurso histórico con el tratamiento de problemas sociales de la España de la época.

Finalmente, el último capítulo toma como punto de partida la propuesta de Carmela Zanelli sobre la configuración narrativa de la Historia general del Perú como una tragedia. Con esto, Rodríguez Mansilla subraya la necesidad de situar el proyecto total del cuzqueño en su siglo áureo, en el que se aspira a una narración armónica, esto es, neoplatónica de la historia. Garcilaso propone una concepción trágica del pasado colonial reciente, pero no de su biografía o de su pasado personal. La destrucción en los Andes por los excesos cometidos en las guerras civiles tanto entre incas como entre conquistadores tendría su explicación última en los «juicios de Dios», que dan cuenta de la imposibilidad de una restitución del reino a cualquiera que no sea la Corona española. Una historia que posee tal carga desoladora, origen de las lágrimas de indios y españoles por igual, necesita de una dosificada inserción de humor que, en específico, sume al propósito didáctico de la empresa historiográfica. El crítico halla en Francisco de Carvajal la figura que permite asegurar el fin edificante de la escritura de la historia, pues no solo encarna una comicidad como paliativo de las atrocidades, sino que es símbolo de una sabiduría neoestoica que se extiende hasta el propio enunciador cuzqueño. Es así como el autor, a partir del estudio del humor y del llanto en la Historia general, prueba una última vez la maestría compositiva del Inca, ajena a los flujos del inconsciente tantas veces «descubiertos».

Sería reduccionista calificar de «hispanista» la lectura de Rodríguez Mansilla, pues la gran distancia que toma el autor es precisamente con toda interpretación que subordine el análisis textual a la cuestión racial en torno al escritor. Resulta interesante que el factor documental sobre la vida social y cotidiana del Inca en la Península parece ser un elemento fundamental de una línea reciente de estudio, desde la que se otorga centralidad a la influencia del círculo de anticuarios andaluces y, en ese sentido, al prestigio social que rodeaba al Inca a partir de su labor en la catedral de Córdoba y su posicionamiento como estudiante esforzado frente a ciertas dificultades de su biografía ${ }^{4}$. Como se ve, este libro presenta una muestra significativa de esfuerzos recientes por ampliar el panorama garcilasista a partir de la localización del cuzqueño en la España andaluza, contexto en el que pasó la mayor parte de su vida.

4. Ver Del Pino, Fermín, «El Inca Garcilaso en el epistolario del licenciado Franco: como persona docta en antiguallas», Revista de Crítica Literaria Latinoamericana, 85, 70, 2017, pp. 73-99; y Cárdenas Bunsen, José, La aparición de los libros plúmbeos y los modos de escribir la historia. De Pedro de Castro al Inca Garcilaso de la Vega, Madrid / Frankfurt am Main, Iberoamericana / Vervuert, 2018. 
En síntesis, la argumentación de la investigación es persuasiva por varios motivos: al realizar una exhaustiva lectura cercana de pasajes relevantes, cotejar todo tipo de fuentes documentales y críticas, y, sobre todo, demuestra conocimiento de los principales mecanismos y principios discursivos dentro del contexto en que el cuzqueño produce y para el que escribe. Si bien, como el propio Rodríguez Mansilla señala en un inicio, no es aún un estudio sistemático desde la perspectiva filológica y aurisecular, El Inca en su Siglo de Oro logra hacer comprender la órbita española desde la cual el cuzqueño se mueve y según la cual propone una lectura conciliadora e imperial de la historia incaica. Provocadora y sugestiva, es un placer leer un estudio que trae nuevas luces sobre un escritor y una obra sobre las que muchas veces parece haberse dicho todo. 